Intervenção em Saúde do Trabalhador

Eliana Aparecida da Silva Pintor ${ }^{\mathrm{a}}$ (iD) https://orcid.org/0000-0002-2585-9116

Andréia De Conto Garbinin ${ }^{\mathrm{b}, \mathrm{c}}$

(iD) https://orcid.org/0000-0003-2787-7470

a Secretaria de Estado da Saúde de São

Paulo. São Paulo, SP, Brasil.

b Pontifícia Universidade Católica de São Paulo. São Paulo, SP, Brasil.

'Universidade Presbiteriana

Mackenzie. São Paulo, SP, Brasil.

Contato:

Andréia De Conto Garbin

E-mail:

andreiagarbin@yahoo.com.br

As autoras informam que o trabalho não foi apresentado em eventos científicos e que não foi baseado em dissertação ou tese.

As autoras declaram que o estudo não foi subvencionado e que não há conflitos de interesses.
Recebido: 09/02/2018

Revisado: 16/07/2018

Aprovado: 25/07/2018

\section{Notificações de violência relacionadas ao trabalho e vigilância em saúde do trabalhador: rompendo a invisibilidade}

\author{
Work-related violence registries and worker's health \\ surveillance: breaking invisibility
}

\section{Resumo}

Introdução: a Política Nacional de Saúde do Trabalhador e da Trabalhadora prevê o replanejamento de ações em saúde do trabalhador a partir do reconhecimento das violências relacionadas ao trabalho. Objetivos: descrever o processo de notificação de violências relacionadas ao trabalho como ferramenta para investigação e intervenção em saúde do trabalhador e as ações decorrentes, por meio de vigilância em saúde do trabalhador, desenvolvidas pelo Centro de Referência em Saúde do Trabalhador (Cerest) de São Bernardo do Campo/SP, no período de 2009 a 2016. Métodos: relato descritivo da atuação do Cerest com base em revisão documental e dados secundários de notificações de violências relacionadas ao trabalho e apresentação e discussão de três ações de vigilância em saúde do trabalhador centradas em aspectos psicossociais. Resultados: as notificações operaram como ferramentas que possibilitaram transformar dados em informações e conhecimento crítico para ação. As vigilâncias foram motivadas por queixas de assédio moral feitas por trabalhadores acidentados em metalúrgica; denúncia e notificações referentes ao adoecimento de trabalhadores em teleatendimento; denúncias de trabalhadores com deficiências em um supermercado. Conclusão: as informações deram visibilidade aos problemas dos trabalhadores e possibilitaram planejamento, pelo Sistema Único de Saúde (SUS), de ações preventivas de enfrentamento à violência e a aspectos psicossociais relacionados ao trabalho.

Palavras-chave: violência no trabalho; saúde do trabalhador; vigilância em saúde do trabalhador; saúde mental; psicologia.

\begin{abstract}
Introduction: the Brazilian National Worker's Health Policy foresees the replanning of workers' health actions based on the recognition of work-related violence. Objectives: to describe the use of work-related violence records as a tool for investigation and intervention actions, through worker's health surveillance, developed by the Occupational Health Reference Center (Cerest) of São Bernardo do Campo, SP, from 2009 to 2016. Methods: descriptive report of the Cerest performance based on documentary review and secondary data of work-related violence records. Presentation and discussion of three surveillance actions focused on psychosocial aspects. Results: the work-related violence reports operated as tools that made it possible to transform data into information and critical knowledge for surveillance actions that were motivated by complaints of moral harassment referred by metallurgy injured workers, denunciations concerning workers sickening in telemarketing and disabled workers in a supermarket. Conclusion: the information gave visibility to the workers' problems and made it possible for the Brazilian National Health System (SUS), through Cerest, to plan preventive actions towards dealing with violence and psychosocial work-related factors.
\end{abstract}

Keywords: workplace violence; occupational health; worker's health surveillance; mental health; psychology. 


\section{Introdução}

Este artigo aborda duas intervenções específicas de práticas em saúde do trabalhador realizadas pelo Centro de Referência em Saúde do Trabalhador (Cerest) do município de São Bernardo do Campo/ SP, no período de 2009 a 2016: as notificações das violências relacionadas ao trabalho e as ações de vigilância em saúde do trabalhador com ênfase nos aspectos psicossociais.

As práticas destacadas convergem no sentido da implicação ética e criativa ${ }^{1}$ que pretende reconhecer as produções existenciais subjetivas e, também, pela valorização do conhecimento dos trabalhadores ${ }^{2,3}$. Muniz e colegas ${ }^{3}$, comentando a contribuição de Ivar Odonne, dizem que "a produção de conhecimento e a intervenção sobre as situações de trabalho [estão] intrinsecamente ligadas à transformação do trabalho e à afirmação da vida" (p. 289).

As notificações das violências integram uma das dimensões contidas nas linhas de cuidado para atenção integral à saúde das pessoas ${ }^{4}$ que conduzem às ações de promoção, proteção e vigilância. As notificações das violências têm caráter compulsório no âmbito da saúde ${ }^{5,6}$ para possibilitar conhecer a gravidade e a magnitude dos casos e subsidiar políticas públicas para a sua prevenção e para a atenção e a promoção da saúde ${ }^{4,7}$.

A Política Nacional de Saúde do Trabalhador e da Trabalhadora ${ }^{8}$ prevê o replanejamento de ações a partir do reconhecimento das violências relacionadas ao trabalho. A identificação dessas violências "poderá instrumentalizar a produção de conhecimentos que fundamentem a elaboração de diagnósticos mais precisos sobre a condição do trabalhador brasileiro" (p. 23) .

No âmbito da saúde pública, tradicionalmente, as violências ocorridas no trabalho foram reconhecidas e inseridas no grupo das "causas externas" de morbimortalidade ${ }^{10,11}$. No entanto, o entendimento da complexidade e da diversidade de situações de violência possibilita constatar que essa análise se torna restritiva para compreensão do fenômeno da violência ${ }^{10}$.

O Sistema Único de Saúde (SUS), a partir de 2006, implantou o Sistema de Vigilância de Violências e Acidentes (Viva) com dois componentes $^{12}$ : (1) vigilância de violência doméstica, sexual e/ ou outras violências interpessoais e autoprovocadas (Viva-Contínuo/Sinan); (2) vigilância de violências e acidentes em emergências hospitalares (VivaSentinela/Inquérito). O objetivo do Sistema Viva é gerar avaliações mais abrangentes sobre o impacto e a caracterização da violência em todas as regiões do país ${ }^{4,7}$.
O Ministério da Saúde adotou a notificação como estratégia central para reconhecer, combater e prevenir a violência e para a articulação de políticas

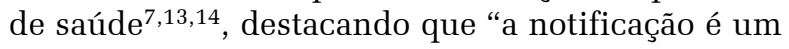
elemento-chave na atenção integral às pessoas, retirando os casos de violência da invisibilidade, prevenindo a violência de repetição e permitindo que a rede de proteção e de garantia de direitos seja acionada e se articule" (p. 9)

No município de São Bernardo do Campo o sistema foi implantado em $2010^{15}$ e estabeleceu a obrigatoriedade da notificação, pelos serviços de saúde do município, dos casos suspeitos ou confirmados de violência incluindo aquelas relacionadas ao trabalho. A estratégia articulou uma Rede de Atenção às Pessoas em Situação de Violência (Reviver) ${ }^{16}$.

Paralelamente à sistematização das informações epidemiológicas relacionadas às violências do trabalho foram estruturadas, no município, as ações de vigilâncias em saúde do trabalhador com foco nas demandas psicossociais.

Visando contribuir na promoção da valorização da vida e da saúde no trabalho, na diminuição dos casos e na mobilização da sociedade para que sejam combatidas todas as formas de violência no trabalho, o objetivo deste relato foi descrever o processo de notificação de violências relacionadas ao trabalho como ferramenta para investigação e intervenção em saúde do trabalhador, e ações decorrentes, por meio de vigilância em saúde do trabalhador, com ênfase em aspectos psicossociais desenvolvidos pelo Cerest do município de São Bernardo do Campo/SP.

\section{Métodos}

Para a elaboração deste relato foram utilizados documentos produzidos pelas equipes da Secretaria de Saúde, no período no período de 2009 a 2016.

Com relação às notificações das violências relacionadas ao trabalho, foram consultados os boletins anuais de divulgação das atividades desenvolvidas e dos resultados alcançados pelo Cerest de São Bernardo do Campo.

As informações relativas às violências em geral foram obtidas nos relatórios produzidos pela equipe do Projeto Reviver.

As ações de vigilâncias apresentadas neste relato foram sistematizadas e divulgadas, de modo genérico, nos relatórios anuais de gestão e nas prestações de contas quadrimestrais. Os dados foram divulgados em eventos temáticos promovidos por diferentes instituições, por exemplo: sindicatos de trabalhadores e instâncias estaduais e regionais de saúde. 
Os procedimentos metodológicos adotados contaram com o reexame dos registros documentais e com a reflexão coletiva dos autores. Foram feitas revisões de documentos e estatísticas, visitas a instituições e discussões nos espaços colegiados da gestão municipal de saúde. A fundamentação teórica e metodológica pautou-se pela produção teórica da saúde pública.

\section{Resultados}

\section{Eventos sentinelas: notificações de violências relacio-} nadas ao trabalho

No Brasil, os casos de violência são de notificação compulsória por meio da ficha de violência interpessoal/autoprovocada, cujos dados são lançados no Sistema de Informação de Agravos de Notificação (Sinan). Nele, consta a identificação da pessoa, a ocupação, local da ocorrência, tipo de violência (física, sexual, psicológica, tortura, negligência, trabalho infantil etc.), meios de agressão, consequências, natureza da lesão, parte do corpo atingida, se a violência está relacionada ao trabalho e se houve abertura de Comunicação de Acidente de Trabalho $(\mathrm{CAT})^{7}$. Há ainda espaço para descrição mais detalhada ${ }^{4}$.

Os profissionais da rede municipal de saúde foram capacitados quanto à identificação e à notificação dos casos de violências relacionadas ao trabalho, em seu caráter epidemiológico e institucional ${ }^{4}$, e não de denúncia ${ }^{7}$.

O Cerest recebia as fichas de notificação ${ }^{16}$ e realizava intervenções junto à rede de saúde, usuários ou familiares, assim como avaliação para ação de vigilância em saúde do trabalhador. A equipe, na condição de autoridade sanitária ${ }^{17}$, foi desafiada a incorporar em sua prática cotidiana a observação dos aspectos psicossociais até então desconsiderados. Inicialmente, foi realizada uma revisão no roteiro de ações de vigilância incluindo também aspectos sobre a organização do trabalho.

As queixas, denúncias ou notificações recebidas pelo Cerest passaram a ser analisadas criteriosamente, desencadeando as seguintes ações estratégicas:

- escuta individual e em grupo de trabalhadores das empresas ${ }^{2}$;

- busca de literatura específica;

- elaboração de questionário com revisão dos trabalhadores e/ou do sindicato da categoria, aplicados na ação de vigilância e/ou no próprio Cerest $^{8}$;
- análise da documentação referente aos aspectos motivacionais, avaliação de desempenho e metas, programas de qualidade de vida e ocupacionais $^{18}$, comunicações de acidentes de trabalho, listas dos afastamentos de acordo com a Classificação Estatística Internacional de Doenças e Problemas Relacionados com a Saúde, $10^{\circ}$ Revisão (CID 10), demitidos e admitidos dos dois últimos anos, escalas de trabalho, laudo ergonômico;

- aplicação de Questionário dos Atos Negativos $(\mathrm{NAQ})^{19}$ adaptado para levantamento de práticas sugestivas de assédio moral ${ }^{20}$;

- convocação dos trabalhadores para orientações coletivas e/ou consulta individual para elucidação de aspectos de organização do trabalho;

- entrevistas com familiares e/ou colegas de trabalho, quando necessário.

A partir da implantação do Projeto Reviver no município e da inserção do Cerest na rede de atenção às pessoas em situação de violência ${ }^{16,21}$, observou-se expressivo aumento das notificações de violência relacionadas ao trabalho ${ }^{22}$. Em 2009 foram registrados três casos, aumentando substancialmente a cada ano: em 2010, 12; em 2011, 31; em 2012, 65; em 2013, 74; em 2014, 99; em 2015, 155 notificações $^{23}$.

No ano de 2015 foram notificadas 135 violências físicas relacionadas ao trabalho, seguidas por 13 psicológicas, quatro autoprovocadas e três sexuais, com destaque, por sua singularidade, para a notificação do cárcere privado de uma agente comunitária de saúde, sequestrada na rua quando se encaminhava para uma visita domiciliar ${ }^{23}$.

A violência autoprovocada (suicídio ou tentativa) relacionada ao trabalho não havia aparecido no ano anterior, o que pode sugerir que houve aprimoramento na investigação dos fatos.

Os dados de violência em São Bernardo do Campo evidenciam um crescimento anual a partir da implantação do projeto específico de atenção (Projeto Reviver), corroborando o achado de outros estudos que revelam o aumento das notificações e da troca de informações e que apontam para a necessidade de capacitar as equipes permanentemente e avançar na atuação intersetorial ${ }^{13,21,22}$.

A análise dos registros revela que agressão física foi a modalidade com maior número de notificações. As mulheres são sempre maioria quando se trata de vítimas de violência ${ }^{13}$.

Das 2.604 violências registradas no município de São Bernardo do Campo em 2015, 155 foram 
relacionadas ao trabalho $(5,9 \%)$, sendo 87 mulheres $(56,1 \%), 54$ homens $(34,8 \%)$ e 14 sem informação (9\%). No quesito raça/cor, 72 referiram cor branca $(46,4 \%), 18$ parda $(11,6 \%), 10$ preta $(6,4)$, um indígena $(0,6 \%)$ e 54 estavam sem preenchimento ou ignoradas $(34,8 \%)^{23}$. Em relação ao local de residência, em torno de $74 \%$ eram de São Bernardo do Campo. As violências concentraram-se na faixa etária de 20-29, com 47 casos, e de 30-39, com $44^{23}$. Quanto à ocupação, destacaram-se profissionais da saúde, seguidos do comércio, segurança, transporte e limpeza.

A investigação das situações de violência no Brasil não tem contemplado as condições de trabalho como fator desencadeador ${ }^{24}$. Na análise de estudos científicos sobre o assunto observa-se não haver menção às questões de violência do trabalho ${ }^{25}$.

No entanto, a violência incide sobre o trabalhador e seu modo de existir. Atinge sua dignidade e repercute no seu sistema de relações sociais. Neste processo, são recorrentes explicações de caráter psicológico e estigmatizante, de modo a desqualificar as experiências vividas pelos trabalhadores e identificá-los como inadequados à sociedade ${ }^{26}$. A violência psicológica acarreta danos ao trabalhador, repercutindo sobre sua condição de saúde e sua subjetividade. Por isso, a intervenção do poder público é necessária para romper com este tipo de prática no ambiente de trabalho.

A experiência em São Bernardo do Campo mostrou a importância de uma atuação em rede para circular as informações de saúde ${ }^{21}$. O aumento de notificações demonstrou a importância do trabalho de sensibilização e treinamento da rede de saúde ${ }^{7,13,22}$.

\section{Vigilâncias nos ambientes de trabalho relativas à violência}

Os procedimentos de notificação anteriormente descritos não são novos ou desconhecidos na área da saúde do trabalhador ${ }^{27,28}$, porém a prática adotada possibilitou a ampliação do olhar técnico e da compreensão sobre os aspectos psicossociais na rotina das ações de vigilância ${ }^{29,30}$.

Foram iniciadas 19 ações de vigilância em ambientes de trabalho com foco nos aspectos relativos à organização do trabalho, nos casos em que havia suspeita ou fatos concretos de violência organizacional e sofrimento e/ou adoecimento mental, sendo três de teleatendimento, três de transporte, três de agências bancárias, entre outras, como metalurgia, comércio, limpeza, saúde privada, plástico e motel.
Serão descritas três intervenções centradas nos aspectos relacionados à organização do trabalho com situações de violência contra trabalhadores:

\section{Queixas de assédio moral por trabalhadores acidenta- dos em metalúrgica}

Trata-se de empresa tradicional, instalada no município, que agrega histórico como espaço privilegiado de trabalho por investir na remuneração dos trabalhadores e no próprio município.

Os trabalhadores começaram a procurar o Cerest individualmente até que se formou um grupo com 11 trabalhadores. Referiam queixas relacionadas a distúrbios osteomusculares, seguidos de assédio moral. Foram realizadas reuniões nas quais os trabalhadores identificaram os riscos presentes no trabalho e descreveram os setores mais problemáticos da empresa, de acordo com a metodologia do mapa de riscos ${ }^{2}$. Os trabalhadores se queixavam de esforços físicos exagerados, a ponto de um trabalhador defecar durante a execução de uma tarefa, e apontavam extremo desconforto, por posturas forçadas, nas áreas de produção.

Os adoecidos pelo trabalho sofriam assédio moral. A empresa perseguia os sindicalizados e fazia controle sistemático, inclusive colocando uma câmera sobre a mesa onde era deixado diariamente o jornal do sindicato.

A empresa foi considerada com riscos psicossociais importantes, pois os trabalhadores apresentavam sintomas depressivos, ideias suicidas, uso de psicotrópicos, palpitações, agressividade e dificuldades para dormir e manter atividades de vida diária.

O Cerest ofereceu um espaço de escuta qualificada, além de consultas médicas, psicológicas e orientações previdenciárias. Depois dessas rodas de conversas, com a participação de dirigentes sindicais, alguns trabalhadores referiram a estratégia de colocar no bolso do macacão, durante o trabalho, um folder sobre assédio moral, produzido pelo Cerest, o que inibiu a atitude de violência de alguns chefes e demonstrou organização coletiva de resistência dos trabalhadores $^{31}$. Na sequência, foi realizada uma ação de vigilância pelo Cerest na qual foram inspecionados os setores identificados pelos trabalhadores como problemáticos e solicitados documentos técnicos relativos às questões de saúde e segurança no trabalho.

De 2006 a 2014, de acordo com CID-10, os benefícios previdenciários concedidos foram, prioritariamente, dos códigos de doenças relacionados aos grupos: $\mathrm{S}$ - lesões, envenenamentos; $\mathrm{M}$ - doenças do sistema osteomuscular e do tecido conjuntivo; F transtornos mentais e comportamentais; $\mathrm{K}$ - doenças 
do aparelho digestivo. A análise do material técnico evidenciou que as doenças ocupacionais não eram reconhecidas como tal e o laudo ergonômico indicava um decréscimo dos distúrbios osteomusculares ao longo dos anos, o que não ocorreu.

Concluída a ação de vigilância, o Cerest realizou reunião com a empresa e representantes da Comissão Interna de Prevenção de Acidentes (Cipa) ${ }^{8,28}$. Um diretor sindical foi convidado para acompanhar a devolutiva da empresa, sendo um elemento surpresa para a mesma naquele momento. A equipe do Cerest notificou a ocorrência do assédio moral e solicitou ações de combate a qualquer tipo de violência.

A empresa apresentou uma proposta de intervenção com foco na cultura de violência organizacional, reconhecendo, dessa forma, a ocorrência das situações de assédio moral referidas pelos trabalhadores. O Cerest manteve o monitoramento, juntamente com o sindicato. Alguns trabalhadores compareceram espontaneamente ao Cerest e relataram mudanças positivas e, em alguns setores, as pressões e ameaças passaram a ser mais brandas ou veladas. Verificou-se que o trabalhador reconfigura seu meio, consegue intervir utilizando sua experiência e não se porta passivamente frente às adversidades ${ }^{32}$.

Os resultados preliminares indicaram o rompimento da invisibilidade e da inacessibilidade das violências praticadas; a aproximação do sindicato e sua consequente ação fiscalizadora; a ciência dada à Cipa como forma de disseminar o fato pela chamada "rede peão" (disseminação informal entre trabalhadores) e, com isso, mais trabalhadores terem conhecimento do Cerest e poderem fazer novas queixas.

Um relatório contando a situação encontrada na empresa foi enviado ao Ministério Público do Trabalho (MPT) para ciência e acompanhamento, pois existiam queixas já acompanhadas pelo órgão. A empresa teve ciência desse encaminhamento, fato que causou desconforto em reunião presencial com o Cerest e manifestação enfática de descontentamento da advogada: "Agora tudo vai para o Ministério Público".

O processo foi marcado pela participação dos trabalhadores e dos representantes institucionais, envolvendo diferentes atores e entidades ${ }^{28}$. Entendemos que o empenho da empresa em apresentar uma proposta de mudança de cultura foi fruto da percepção, por parte deles, de que havia muitos agentes envolvidos.

\section{Vigilância em empresa de teleatendimento de grande porte}

Em 2014, o Cerest recebeu trabalhadoras de empresa de teleatendimento e, paralelamente, os médicos da rede de saúde informaram sobre a ocorrência de otite de repetição em várias operadoras de telemarketing. Nos encontros de apoio matricial nas Unidades Básicas de Saúde, com toda a equipe reunida para tratar do tema de saúde do trabalhador, os médicos denunciaram que eram criadas dificuldades para as gestantes irem ao banheiro, o que originava infecções urinárias, podendo causar prematuridade e complicações no parto. Também relataram transtornos mentais em vários trabalhadores e problemas com a empresa para aceitação de atestados médicos emitidos por eles.

O Cerest se debruçou sobre o caso da empresa em virtude das inúmeras reclamações e registros de trabalhadores adoecidos. Foram realizadas inspeções, em 2014 e 2015, com a aplicação de questionário referente à identificação dos riscos ocupacionais e da condição de saúde (revisado por sindicalista) ${ }^{28}$. As queixas relacionadas aos aspectos psicossociais incluíam metas abusivas, pressão por resultados, conflitos éticos causados por instruções obscuras ou alta pressão por resultados, tempo insuficiente para realizar as atividades, impossibilidade de acompanhar a parte variável do salário, perda de prêmio pelo trabalhador por falta injustificada, mesmo tendo cumprido a meta estabelecida, assédio moral como forma de coação para cumprimento de metas. A organização do trabalho - compreendida como o modo como as tarefas são divididas, os tempos, os ritmos, a duração da jornada, a forma de remuneração, a estrutura hierárquica, incluindo as condições físicas, químicas, térmicas e psicossociais das situações profissionais (pressão, tensão, injustiça) ${ }^{33,34}$ indicava um ambiente configurado para promover o desgaste mental, produto de uma correlação desigual de poderes impostos sobre a atividade laboral e os trabalhadores, de forma a acionar forças que incidem no processo biopsicossocial da saúde-doença. Trata-se de uma correlação de poderes e forças em que o executante do trabalho se torna perdedor ${ }^{34}$.

Dos 614 questionários entregues aos trabalhadores, foram obtidas 606 respostas que revelaram a ocorrência de violência psicológica, esgotamento mental, assédio moral, infecções urinárias e dores musculares ${ }^{35}$. As inadequações foram registradas em um auto de infração com a devida base legal e que se desdobrou no seu cumprimento.

As trabalhadoras de nove áreas da empresa responderam aos questionários, a maioria mulheres, com idade entre 18 e 29 anos, com menos de um de trabalho na empresa. De modo geral, referiram que realizavam horas-extras, não sentiam pressão e que nem sempre o pagamento era cumprido conforme acordado; trabalhavam sob regime de metas, sendo os resultados alcançados expostos a toda equipe verbalmente. Nas avaliações de desempenho foram verificadas as metas alcançadas, a frequência, a 
agilidade no atendimento, a gentileza com o cliente e o número de atendimentos ${ }^{35}$.

Foram referidos pelos trabalhadores outros problemas relacionados às condições de trabalho: as pausas e horários de almoço eram insuficientes; pouca ou ineficiente manutenção do equipamento (head set, computadores, mobiliário etc.); o ambiente de trabalho foi descrito como acelerado, competitivo, monótono, inibidor, prazeroso, estimulante, barulhento, depressivo, estressante, cansativo, ruim, injusto, entre outras. Relativo aos aspectos psicossociais, referiram violência psicológica por parte dos clientes, tais como: xingamentos, gritos e humilhações, tratadas pela empresa como parte habitual do trabalho ${ }^{35}$.

Os aspectos relacionados à condição de saúde citados pela maioria dos trabalhadores foi o esgotamento mental, dores de cabeça, rinite/sinusite/ alergia; dores nas costas, vista cansada, irritação/ nervosismo, cansaço/fadiga e uso de medicação ${ }^{35}$. Também foram referidos sintomas depressivos e cansaço. As formas de discriminação experimentadas referiram-se à religião, sexo e orientação sexual, idade, cor/raça, classe social e deficiência física. Destaca-se, ainda, que as trabalhadoras não estavam satisfeitas quanto à condição de trabalho durante o período gestacional ${ }^{35}$.

As informações descritas associadas às inspeções da equipe de vigilância em saúde do trabalhador e às conversas informacionais durante essa ação permitiram concluir e indicar que: havia desconforto com o modo como as tarefas eram distribuídas, cobradas e avaliadas, as quais interferiam na possibilidade de se alcançar os resultados esperados. Ainda geravam tensão, humilhação e punição, provocando um processo lento e desgastante com prejuízos à saúde física e mental; insatisfação com o grau de limpeza e conforto, que atingem a dignidade e levam a sentimentos de menos valia e tristeza; constante vigilância e metas que causam ansiedade pelo caráter coercitivo que adquirem ${ }^{36}$; além da tensão nervosa devido ao aceleramento das tarefas, já abordado por Le Guillant et al., em $1956^{37}$. A pressão por metas induzia os profissionais a conflitos éticos ${ }^{38}$, situações em que as exigências da empresa contrariam os valores pessoais. Por exemplo: o setor de cancelamento de serviços tinha um "teto de cancelamentos", ao atingi-lo os teleoperadores eram obrigados a enganar os clientes confirmando que cancelaram os produtos quando, na verdade, não realizavam os procedimentos solicitados no sistema. Essa situação repercutia de duas formas: a solicitação não atendida gerava novo contato do cliente, as "rechamadas", quando, possivelmente, o cliente estaria mais irritado e desrespeitoso; por outro lado, gerava um conflito ético nos operadores, por se sentirem desonestos, o que os predispõem ao sofrimento mental e, posterior, desenvolvimento de adoecimento psíquico ${ }^{39}$.

Destaca-se, ainda, o assédio moral organizacional por meio da manutenção de práticas de gestão autoritárias. Os gestores utilizavam do sistema de "ranqueamento" de trabalhadores, tanto por papel e por sistema, como verbalmente, estimulando a competição entre os trabalhadores e expondo-os em situações negativas ${ }^{18}$.

Os dados evidenciaram que: há uma predileção pela contratação de um público jovem (61\% entre 18-29 anos), possivelmente para suportar o desgaste; existe alta rotatividade, o que atesta a insatisfação e o impacto das situações negativas no trabalho, também descrito como o tempo de vida útil na categoria (cerca de dois anos), ou uma atividade que não é reconhecida como profissã ${ }^{40}$; há incerteza sobre o real salário a ser recebido no final do mês, fator que pode gerar instabilidade emocional; a análise do ambiente de trabalho tem muitos aspectos negativos. Ao que parece, ao final essas condições se traduzem para a maioria em esgotamento emocional. Todos os aspectos em sinergia vão caracterizar uma violência gestionária, descrita em estudos sobre call centers ${ }^{41}$.

Após as ações de vigilância as queixas diminuíram e a empresa ficou sob monitoramento e inspeções regulares. Referente à manifestação da empresa, a primeira proposta de intervenção apresentada mostrou-se insuficiente quanto às mudanças na cultura organizacional com foco no respeito nas relações e a abolição das práticas violentas. Em reuniões com a equipe do Cerest, foi discutida a necessidade de implementar mudanças relacionadas ao uso do banheiro pelas gestantes e apresentada a contradição de ter um programa de incentivo ao pré-natal e, ao mesmo tempo, não prover um ambiente de respeito à condição da gestante.

As informações foram remetidas ao Ministério Público do Trabalho e ao Ministério do Trabalho, pois várias informações obtidas referiam-se à violação de direitos trabalhistas.

Este caso mostrou a importância da integração entre Cerest e a rede de saúde.

Foi dada devolutiva aos psicólogos da rede de saúde e solicitou-se aos profissionais da atenção básica auxílio no monitoramento para que mantivessem o Cerest informado sobre novas ocorrên$\operatorname{cias}^{7}$, reiterando a parceria e a necessidade de ações integradas.

\section{Trabalhadores com deficiência: por vezes, a inclusão perversa}

Neste tópico destacam-se casos de trabalhadores com deficiência para salientar a necessidade de 
fiscalização nos ambientes de trabalho com foco nas condições de saúde desses profissionais, pois, muitas vezes, encaram a oportunidade de trabalho como um favor, submetendo-se a condições que desrespeitam a dignidade humana nos ambientes de trabalho.

Uma trabalhadora de um supermercado, 39 anos, casada, ensino médio completo, dez anos de trabalho na empresa, com sequelas de poliomielite na marcha, procurou o Cerest, a partir de um cartaz sobre doenças do trabalho, para saber sobre a CAT. Referiu dores musculares e situações de assédio moral vivenciadas por trabalhadores com deficiência. Relatou que já trabalhava no supermercado quando o serviço médico da empresa a transferiu para a função de operadora de caixa e passou a ser considerada trabalhadora com deficiência para fins de cumprimento da Lei de Cotas. Ocorre que a nova função agravou suas dores na coluna. Solicitou nexo causal e recolocação no setor. A médica do trabalho do Cerest solicitou mudança de função.

A mesma trabalhadora relatou a situação de um trabalhador surdo, contratado pelo supermercado pela Lei de Cotas, cuja função era arrumar as prateleiras no setor de panelas. Ocorria que muitas vezes os clientes o chamavam para tirar dúvidas e numa dessas ocasiões, após ter sido chamado várias vezes, permaneceu de costas. O cliente considerou que ele não o atendeu e o agrediu fisicamente, desferindo-lhe um soco. $\mathrm{O}$ trabalhador ficou traumatizado e solicitou a demissão do emprego.

Uma jovem trabalhadora com deficiência intelectual permanecia em pé durante toda a jornada de trabalho, na porta do supermercado, "plantada como uma árvore", para dar orientações aos clientes e era motivo de gozação pelos colegas. Um jovem trabalhador com deficiência intelectual arrumava os carrinhos do supermercado no pátio. Os colegas o deixavam sozinho, ele percebeu e pediu desligamento.

O Cerest realizou fiscalização no local buscando uma estratégia de análise ampla da empresa para chegar até os postos de trabalho dos trabalhadores com deficiência. A equipe elencou questões relacionadas à ergonomia e solicitou programa de adequação. Foram promovidas atividades de educação permanente com representantes do Conselho Nacional dos Direitos da Pessoa com Deficiência (Conade) e do Cerest estadual, para atividade de formação da equipe.

Esses casos denotam que a empresa que esteve sob ação de vigilância não atuava na perspectiva da inclusão do trabalhador com deficiência. Assim como outras empresas que se mantêm alheias às exigências legais sobre a inclusão que asseguram à pessoa com deficiência um ambiente acessível e inclusivo ${ }^{42,43}$.

O relato da denunciante explicita a naturalização da inferioridade relativa à inclusão no trabalho das pessoas com deficiência que se revela quando elas são absorvidas em atividades ou cargos que não consideram suas reais qualificações. A naturalização da desqualificação profissional das pessoas com deficiência é uma construção simbólica vivenciada a partir do binômio desemprego e exclusão ${ }^{44}$.

\section{Considerações finais}

A produção científica referente às violências relacionadas ao trabalho ainda é incipiente. A notificação de violência relacionada ao trabalho pela rede de saúde pública municipal representou uma importante estratégia para o desencadeamento de ações de prevenção e promoção à saúde do trabalhador. Nas ações de vigilância em saúde do trabalhador foram abordados os riscos psicossociais, geralmente negligenciados nas ações de vigilância ${ }^{29} \mathrm{e}$ nas rotinas dos Cerest.

Muitos desafios ${ }^{13,29}$ precisam ser superados para que essas ações sejam efetivas. As equipes de trabalho precisam atualizar seus dispositivos tecnológicos de intervenção diante dos múltiplos cenários do mundo do trabalho atual. Os números de casos de notificação compulsória dos agravos relacionados ao trabalho estão longe de se aproximarem do mundo real vivido pela classe trabalhadora ${ }^{13,24}$. Por meio da experiência relatada espera-se contribuir para o diálogo com a rede de saúde em relação a novas formas de intervenção em saúde do trabalhador relacionadas às violências no trabalho.

\section{Contribuição de autoria}

As autoras contribuíram igualmente no levantamento e na interpretação das informações, na elaboração do manuscrito e na aprovação da versão final publicada, e assumem integral responsabilidade pelo seu conteúdo.

\section{Agradecimento}

Agradecemos a contribuição do Prof. Dr. Ademar Arthur Chioro dos Reis na revisão crítica do manuscrito. 


\section{Referências}

1. Maraschin C. Pesquisar e intervir. Psicol Soc. 2004;16(1):98-107.

2. Oddone I, Marri G, Gloria S. Ambiente de trabalho: a luta dos trabalhadores pela saúde. São Paulo: Hucitec; 1986.

3. Muniz HP, Brito J, Souza KR, Athayde M, Lacomblez M. Ivar Oddone e sua contribuição para o campo da Saúde do Trabalhador no Brasil. Rev Bras Saude Ocup. 2013;38(128):280-91.

4. Brasil. Ministério da Saúde. Notificação de violências interpessoais e autoprovocadas [Internet]. Brasília, DF: Ministério da Saúde; 2017 [acesso em 11 jan 2018]. Disponível em: http://portalarquivos. saude.gov.br/images/pdf/2017/fevereiro/07/cartilha notificacao_violencias_2017.pdf

5. Brasil. Ministério da Saúde. Portaria de consolidação $\mathrm{n}^{\circ}$ 4, de 28 de setembro de 2017. Consolidação das normas sobre os sistemas e os subsistemas do Sistema Único de Saúde. Diário Oficial da União. 3 out 2017.

6. Brasil. Ministério da Saúde. Portaria de consolidação $n^{\circ}$ 5, de 28 de setembro de 2017. Consolidação das normas sobre as ações e os serviços de saúde do Sistema Único de Saúde. Diário Oficial da União. 3 out 2017. Seção 1:360.

7. Garbin CAS, Dias IA, Rovida TAS, Garbin AJI. Desafıos do profıssional de saúde na notifıcação da violência: obrigatoriedade, efetivação e encaminhamento. Cien Saude Colet. 2015;20(6):1879-90.

8. Brasil. Ministério da Saúde. Portaria $n^{0} 1.823$, de 23 de agosto de 2012. Institui a Política Nacional de Saúde do Trabalhador e da Trabalhadora. Diário Oficial da União. 24 ago 2012. Seção 1:46-51.

9. Oliveira RP, Nunes MO. Violência relacionada ao trabalho: uma proposta conceitual. Saude Soc. 2008;17(4):22-34.

10. Minayo MCS. Violência social sob a perspectiva da saúde pública. Cad Saude Publica. 1994;10(1):S7-S18.

11. Santos Júnior ÉA, Dias EC. Violência no trabalho: uma revisão da literatura. Rev Bras Med Trab. 2004;2(1):36-54.

12. Brasil. Ministério da Saúde. Viva: vigilância de violências e acidentes: 2013 e 2014 [Internet]. Brasília, DF: Ministério da Saúde; 2017 [acesso em 11 jan 2018]. Disponível em: http://bvsms.saude. gov.br/bvs/publicacoes/viva_vigilancia_violencia acidentes_2013_2014.pdf

13. Veloso MMX, Magalhães CMC, Dell'Aglio DD, Cabral IR, Gomes MM. Notificação da violência como estratégia de vigilância em saúde: perfil de uma metrópole do Brasil. Cien Saude Colet. 2013;18(5):1263-72.

14. Farias MS, Souza CS, Carneseca EC, Passos ADC, Vieira EM. Caracterização das notificações de violência em crianças no município de Ribeirão
Preto, São Paulo, no período 2006-2008. Epidemiol Serv Saude. 2016;25(4):799-806.

15. São Bernardo do Campo. Secretaria de Saúde. Resolução GSS n ${ }^{0}$ 7, de 16 de setembro de 2010. Estabelece a notificação obrigatória dos casos suspeitos ou confirmados de violência pelos serviços de saúde do município, públicos e privados. Notícias do Município. 24 set 2010.

16. Garbin ADC, Chioro A, Pintor EAS. Rede de Atenção às pessoas em situação de violência relacionada ao trabalho: investigação dos casos pelo Cerest SBC/SP. In: Villar EB, Caputo M, Coria EA, Gimenez M, compiladores. Hostigamiento psicológico laboral e institucional en Iberoamérica: estado del arte y experiencias de intervención. Buenos Aires: SB Editorial; 2015. p. 233-42.

17. São Paulo (Estado). Lei no 10.083, de 23 de setembro de 1998. Dispõe sobre o Código Sanitário do Estado [Internet]. Diário Oficial. 24 set. 1998 [acesso em 30 jan 2018]. Disponível em: https:// www.al.sp.gov.br/repositorio/legislacao/lei/1998/lei10083-23.09.1998.html

18. Lima CQB, Barbosa CMG, Mendes RWB, Patta CA. Assédio moral e violência no trabalho: caracterização em perícia judicial. Relato de experiência no setor bancário. Rev Bras Saude Ocup. 2014;39(129):101-10.

19. Einarsen S, Hoel H. The negative acts questionnaire: development, validation and revision of a measure of bullying at work. In: Proceedings of the 10th European Congress on Work and Organisational Psychology; 2001 May 16-19; Prague.

20. Gonçalves RC. O assédio moral no Ceará: naturalização dos atos injustos no trabalho [dissertação]. Fortaleza: Universidade de Fortaleza; 2006.

21. Njaine K, Assis SG, Gomes R, Minayo MCS. Redes de prevenção à violência: da utopia à ação. Cien Saude Colet. 2006;11:1313-22.

22. Galdino A, Santana VS, Ferrite S. Os centros de referência em Saúde do Trabalhador e a notificação de acidentes de trabalho no Brasil. Cad Saude Publica. 2012;28(1):145-59.

23. São Bernardo do Campo. Centro de Referência em Saúde do Trabalhador. Vigilância Ambiental. Boletim Cerest e Vigilância Ambiental, $n^{\circ} 1$. São Bernardo do Campo: Secretaria de Saúde de São Bernardo do Campo; 2016.

24. Nobre LCC. Trabalho precário e mortes por acidentes de trabalho: a outra face da violência e a invisibilidade do trabalho [tese]. Salvador: Universidade Federal da Bahia; 2007.

25. Schraiber LB, D’Oliveira AFPL, Couto MT. Violência e saúde: estudos científicos recentes. Rev Saude Publica [Internet]. 2006 [acesso em 15 fev 2018];40:112-20. Disponível em: 
http://www.scielo.br/scielo.php?pid=S003489102006000400016\&script $=$ sci_abstract\&tlng $=$ pt

26. Garbin ADC, Fischer FM. Assédio moral no trabalho e suas representações na mídia jornalística. Rev Saude Publica. 2012;46(3):417-24.

27. Machado JMH. A propósito da vigilância em Saúde do Trabalhador. Cien Saude Colet. 2005;10(4):987-92.

28. Vasconcellos LCF, Gomez CM, Machado JMH. Entre o definido e o por fazer na Vigilância em Saúde do Trabalhador. Cienc Saude Colet. 2014;19(12):4617- 26.

29. Vilela RAG, Almeida IM, Gomes MHP, Gemma SFB, Jackson Filho JM, Duracenko SRC, et al. A expansão do objeto da vigilância em acidente do trabalho: história e desafios de um centro de referência em busca da prevenção. Cienc Saude Colet [Internet]. 2016 [acesso em 11 jul 2018]. Disponível em: http://www.cienciaesaudecoletiva. com.br/artigos/a-expansao-do-objeto-da-vigilanciaem-acidente-do-trabalho-historia-e-desafiosde-um-centro-de-referencia-em-busca-daprevencao/15880

30. Gomez CM, Vasconcellos LCF, Machado JMH. Saúde do trabalhador: aspectos históricos, avanços e desafios no Sistema Único de Saúde. Cien Saude Colet. 2018;23(6):1963-70.

31. Sato L. Astúcia e ambiguidade: as condições simbólicas para o planejamento negociado do trabalho no chão de fábrica [tese]. São Paulo: Universidade de São Paulo; 1998.

32. Silva CAF. A gestão de si na reinvenção das normas: práticas e subjetividade no trabalho. Saude Soc. 2008;17(4):111-23.

33. Brasil. Ministério da Saúde. Doenças relacionadas ao trabalho: manual de procedimentos para os serviços de saúde. Brasília, DF: Ministério da Saúde; 2001.

34. Seligmann-Silva E. Trabalho e desgaste mental: o direito de ser dono de si mesmo. São Paulo: Cortez; 2011.
35. Garbin ADC, Marchi CR, Moya E, Pintor E, Peixoto RB, Brasil RC. Vigilância em Saúde do Trabalhador com foco nos riscos psicossociais em empresa de teleatendimento de São Bernardo do Campo. In: Anais do $30^{\circ}$ Congresso de Secretários Municipais de Saúde do Estado de São Paulo; 13-15 abr 2016; São Paulo.

36. Assunção AA, Marinho-Silva A, Vilela LVO, Guthier ML. Abordar o trabalho para compreender e transformar as condições de adoecimento na categoria dos teleatendentes no Brasil. Rev Bras Saude Ocup. 2006;31(114):47-62.

37. Le Guillant L, Roelens R, Bégoin J, Béquart P, Hamsen M, Lebreton F. A neurose das telefonistas. Rev Bras Saude Ocup. 1984;47(12):7-11.

38. Dejours C. A banalização da injustiça social. Rio de Janeiro: Fundação Getúlio Vargas; 1999.

39. Pintor EAS. Sofrimento mental em vendedores na Grande São Paulo: a destituição do ser pela organização do trabalho. Rev Bras Saude Ocup. 2010;35(122):277-88.

40. Oliveira S, Jacques MGC. Políticas e práticas de gestão e saúde: recortes sobre o trabalho de teleatendimento no Rio Grande do Sul. Rev Bras Saude Ocup. 2006;31(114):63-72.

41. Metzger JL, Maugeri S, Benedetto-Meyer M. Predomínio da gestão e violência simbólica. Rev Bras Saude Ocup. 2012;37(126):225-42.

42. Vasconcelos FD. O trabalhador com deficiência e as práticas de inclusão no mercado de trabalho de Salvador, Bahia. Rev Bras Saude Ocup. 2010;35(121):41-52.

43. Garcia VG. Panorama da inclusão das pessoas com deficiência no mercado de trabalho no Brasil. Trab Educ Saude. 2014;12(1):165-87.

44. Garbin ADC. A vivência de trabalho da pessoa com deficiência e as repercussões à saúde [tese]. São Paulo: Universidade de São Paulo; 2016. 